\title{
PERSPECTIVAS E POSSIBILIDADES PARA A RENOVAÇÃO DA FORMAÇÃO PROFISSIONAL EM EDUCAÇÃO FÍSICA NO CAMPO DA SAÚDE1
}

\author{
Paulo Magalhães Monard Nascimento \\ Universidade Federal do Amapá, Macapá, Amapá, Brasil \\ Marcio Romeu Ribas de Oliveira \\ Universidade Federal do Rio Grande do Norte, Natal, Rio Grande do Norte, Brasil
}

\begin{abstract}
Resumo
Este estudo objetivou analisar apontamentos e perspectivas que contribuem para consolidação de nova maneira de pensar a formação em Educação Física para o campo da saúde, num recorte que explicita as dimensões política, prática e pedagógica concernentes a esse processo formativo. Trata-se de uma pesquisa bibliográfica, de natureza conceitual, que identifica as contribuições de um grupo de autores e autores, com forte afinidade com a área das ciências humanas e sociais, vinculados tanto ao campo da saúde quanto ao campo da Educação Física, para uma renovação curricular da formação dessa área. As afinidades com a Saúde Coletiva, o conceito de práticas corporais, o trabalho vivo em ato e as tecnologias leves representam a síntese dos apontamentos elaborados.
\end{abstract}

Palavras-chave: Formação Profissional; Educação Física; Saúde.

\section{Introdução}

Mudanças concretas acerca da formação dos profissionais do campo da saúde ainda são um tanto tímidas, especialmente se tratarmos da atuação profissional voltada para a esfera da saúde pública, no sentido da relevância/transformação social. Embora o profissional/professor de Educação Física (EF) componha atualmente as principais políticas públicas de saúde, como a Política Nacional de Promoção da Saúde e o Núcleo de Apoio à saúde da família, sabe-se que historicamente o mesmo não possui uma formação inicial inclinada para esse campo de intervenção profissional.

$\mathrm{Na}$ realidade, os processos formativos, a nível de graduação, responsáveis pela formação inicial, ainda estão hegemonicamente distantes dos debates críticos de mudança para o setor desenvolvidos nos últimos 25 anos, assim, mantendo características ainda conservadoras, que consideram o processo de formação como, prioritariamente, a atualização técnica e científica. Sabe-se que as construções formativas tradicionais no âmbito da saúde são biologizadas, conteudistas, fragmentadas, centradas na instrução técnica e mecanicista. Historicamente, essa estrutura pedagógica de educação profissional prevê a construção de conhecimento compartimentalizado, segmentando o ser humano em partes passíveis de serem analisadas em separado (CECCIM; FEUERWERKE, 2004).

Um pensamento crítico sobre a formação profissional em saúde vem se desenvolvendo nos últimos anos, incluindo a EF. Fundamentada na Saúde Coletiva, a graduação em EF, na estratégia de mudança no cenário da formação em saúde, ganha uma proposta muito mais

\footnotetext{
${ }^{1} \mathrm{O}$ presente trabalho não contou com apoio financeiro de nenhuma natureza para sua realização.
} 
afinada com uma prática cuidadora, pensada para a atenção integral de indivíduos e coletivos, que extrapola a dimensão biológica do corpo. Essa perspectiva está relacionada, dentre outras coisas, a uma ideia que amplia o conceito de saúde, contemplando aspectos sociais, subjetivos, históricos, afetivos, culturais.

Tal processo de mudança interna na EF, não obstante, demonstra-se ainda muito sutil, ante significativa resistência das tradições curriculares técnico-esportiva e médico-científica (FRAGA; CARVALHO; GOMES, 2012). Nessa direção, o estudo objetivou analisar apontamentos e perspectivas que contribuem para consolidação de nova maneira de pensar a formação em EF na saúde, num recorte que explicita as dimensões política, prática e pedagógica concernentes a esse processo formativo. Trata-se de uma pesquisa bibliográfica, de natureza conceitual, que identifica as contribuições de um grupo de autores e autores, com forte afinidade com a área das ciências humanas e sociais, vinculado tanto ao campo da saúde quanto ao campo da EF, para uma renovação curricular da formação dessa área.

\section{Apontamentos e perspectivas para a formação em Educação Física na saúde}

Para discutir mudanças para a formação em EF no campo da saúde, é necessário entender preliminarmente que o campo da formação profissional em qualquer carreira que seja, é um território de dilemas, conflitos e tensões. Logo, neste texto, distantes do discurso da certeza, daremos visibilidade a uma parte do que um grupo de autores e autoras, considerados progressistas e com forte afinidade com as ciências humanas e sociais, vinculados tanto ao campo da saúde quanto ao da EF em específico, vem desenvolvendo/construindo, nos últimos anos, acerca de elementos potencialmente capazes de contribuir na elaboração de outra lógica para formação em EF no campo da saúde.

Vale destacar que os aspectos da formação, classificados aqui de maneira simplificada, como de ordem política, prática e pedagógica, na realidade compõem dimensões de um todo. Dessa forma, eles não existem isoladamente, mas em inter-relação, de maneira interdependente, em que um reverbera sobre o outro num movimento constante e nem sempre hierárquico. De qualquer maneira, pela orientação didática assumida neste texto, os temas serão apresentados a partir das especificidades da natureza de cada uma destas dimensões.

\section{Outra/Nova Perspectiva: Política}

A dimensão política representa a tomada de decisão ante uma fundamentação sobre a lógica argumentativa, ideológica e até mesmo conceitual da formação. Isto representa que as práticas de ensino na formação profissional não são neutras, mas sim carregam uma intencionalidade, pois refletem, mesmo que de forma não consciente, a defesa de um dado projeto social. Nesse caso da formação em EF, não ganham centralidade, por exemplo, apenas as discussões sobre a concepção de ser humano crítico e de sociedade emancipada, mas principalmente, a concepção de saúde a ser assumida.

Pensamos aqui, rompendo com a tradição das ciências da saúde, em defender um conceito de saúde mais próximo ao ponto de vista levantado por Canguilhem (2009, p. 78), que percebe os processos saúde-doença como inerentes à dinâmica da vida, considerando a possibilidade/capacidade de adoecer e se recuperar, de maneira a representar a saúde como uma "margem de tolerância às infidelidades do meio", mas, principalmente, por afirmar que as categorias da saúde e da doença são reconhecidas pela vida no plano da experiência, enquanto provação em sentido afetivo e não no plano da ciência.

Sobre outro aspecto, é interessante situar a saúde no entorno de uma abordagem que a entenda como um direito social e, portanto, como cidadania. Minayo, Hartz, Buss (2000), afinados com a própria lógica adotada na Constituição Federal (BRASIL, 1988) e na Lei 
Orgânica de Saúde brasileira (BRASIL, 1990), circunscrevem a saúde atrelada ao conceito de qualidade de vida, a partir do respeito à satisfação de necessidades consideradas elementares da vida, levando em consideração justamente condicionantes como trabalho, renda, habitação, alimentação, lazer, acesso a serviços de saúde.

A partir dessas considerações, legitima-se pensar a aproximação entre EF e Saúde Coletiva como a representação de um caminho possível para renovação curricular. Historicamente, ressentida dos limites existentes na formação baseada na abordagem com enfoque biológico da saúde, a EF pode encontrar no campo da Saúde Coletiva vazão para explorar as dimensões esféricas do corpo e do movimentar-se, sobretudo do ponto de vista social. Essa aproximação certamente representa um outro modo de conceber não só a saúde e o corpo, mas a própria vida.

Carvalho (2005) entende que a EF não será capaz de interferir no fenômeno saúdedoença se não for capaz de ressignificar sua tradição alicerçada no biológico e, enfím, possa dar relevância para o social, o público, o coletivo, centrando assim a atenção não mais na doença e seus fatores de risco, mas sim na saúde, no bem-estar e na qualidade de vida. Para Palma (2001, p. 24) parece ser ingenuidade concordar que o único modo de se analisar o processo saúde-doença seja através dos seus determinantes biológicos. "O adoecer humano não deve ser investigado ou tratado somente sob a forma de uma relação biológica de causa e efeito, tão simples, que desconsidere outros aspectos relevantes, tais como os contextos socioeconômicos e históricos".

Ainda na abordagem de Carvalho (2005, p. 103), a Saúde Coletiva é justamente um campo de produção do conhecimento e intervenção profissional que tem como objeto de estudo "as necessidades sociais de saúde com intuito de construir possibilidades interpretativas e explicativas dos fenômenos relativos ao processo saúde-doença, visando a ampliar significados e formas de intervenção". De fato, a Saúde Coletiva, ao reagir ao positivismo e ao foco no modelo biomédico, privilegia realmente o debate nos aspectos coletivos, públicos e sociais, visando ainda compor campo científico tendo como base o social na compreensão do fenômeno saúde-doença (FREITAS; BRASIL; SILVA, 2006).

Palma (2001) concorda que uma infinidade de estudos vêm sendo desenvolvidos em defesa dos mais diversos benefícios para a saúde advindos da prática sistematizada de atividade física, contudo o autor percebe que esses mesmos estudos estão vinculados a uma visão de saúde muito estreita, que entende que a doença pode ser evitada especialmente por ação única do próprio indivíduo, apenas de modo determinista-biológico e desatento a contextos socioeconômicos.

Vale destacar que foi apenas nos anos de 1980 que o campo da EF foi desenvolvendo uma crítica ao modelo biomédico e foi progressivamente construindo uma afinidade com as ciências humanas e sociais. Ainda assim, em função de uma rígida organização compartimentada do conhecimento e do interesse de se agregar uma legitimidade científica ao campo, a EF, numa relação de tensão, se edifica enquanto área da saúde e se vincula, hegemonicamente, ao arcabouço teórico-conceitual e metodológico do campo biomédico. Embora seja evidente a consolidação das áreas socioculturais e pedagógicas na EF, o diálogo democrático entre as demais áreas de conhecimento, sobretudo no que diz respeito às temáticas da saúde, ainda é difícil. (CARVALHO, 2005).

De qualquer maneira, tomar a Saúde Coletiva e, por conseguinte, o referencial das ciências humanas como fundamento, significa compreender a EF e a própria saúde dando legitimidade para a vida e os múltiplos e complexos determinantes das ações humanas, percebendo as influências culturais, condições de vida e as distintas possibilidades de acesso a bens e serviços como condicionantes do modo de viver e, ainda, compreendendo o ser humano socialmente, sem segmentá-lo, reduzi-lo ou mesmo universalizá-lo (FREITAS; BRASIL; SILVA, 2006). 
Logo, o encontro possível entre EF e Saúde Coletiva claramente sinaliza para o caminho do exercício do intercâmbio entre as diversas áreas do conhecimento para captar o fenômeno saúde-doença, entendendo que tal fenômeno atravessa diferentes campos disciplinares, sendo, portanto, da esfera transdisciplinar. Essa aproximação dá sentido a uma política de formação em EF que encontra na lógica da democratização do acesso ao acervo da cultura corporal um de seus principais fundamentos. Nessa lógica, as ginásticas, os esportes, os jogos, a dança, as lutas se localizam enquanto formas do cuidado da saúde na perspectiva esférica e, sobretudo, como um direito social, assim, tendo de se tornar acessível a toda população.

Naturalmente, pensar a democratização do acesso às experiências da cultura corporal no âmbito da saúde, nos remete a pensar o Sistema Único de Saúde (SUS) como lugar privilegiado para essa política se estabelecer. Portanto, vale destacar a universalidade e a igualdade de acesso aos serviços como princípios do SUS e, portanto, como valores a serem assumidos na formação.

Ainda na esfera dos princípios do SUS, podemos considerar a integralidade como elemento também fundamental para ressignificar a formação em EF, especialmente na dimensão política, muito embora a integralidade tenha forte reverberação e até mesmo presença direta nas dimensões prática e pedagógica. Percebido com uma riqueza polissêmica (AYRES et al., 2012), o princípio da integralidade, sendo do próprio SUS, implica a percepção ampliada não só da saúde, mas do ser humano e das demandas oriundas dessa outra visão. Na EF, isso desencadeia a expansão do próprio entendimento sobre o corpo e expande também a percepção das necessidades sociais dos usuários.

Dessa forma, ações que tratavam de uma maneira unidimensional o processo de cura de agravos ou mesmo de prevenção e promoção passam a ser insuficientes ou talvez até mesmo ineficazes para dar conta desta forma mais esférica de conceber à saúde. Acredita-se que, nesse âmbito, seja muito mais coerente a perspectiva da produção do cuidado ${ }^{2}$ na atenção à saúde.

Feitas essas opções conceituais, consideramos o entendimento sobre Práticas Corporais como elemento sintetizador dessas mudanças explicitadas acima. Normalmente, o termo Prática Corporal é de fato mais usado por autores que buscam um desprendimento da condição unicamente biomecânica do movimento humano, sendo comum a utilização da expressão Práticas Corporais para materializar uma dimensão mais complexa do ser humanos em movimento ou do movimentar-se, que também considera, ou mesmo privilegia, as contribuições das ciências sociais e humanas.

Diferente da semântica do termo atividade física, que compreende o movimento humano no sentido do gasto energético para além do estado basal (MANIFESTO, 2000; McARDLE, KATCH, KATCH, 2008), para Carvalho (2006, p. 34) “As práticas corporais são componentes da cultura corporal dos povos, dizem respeito ao homem em movimento, à sua gestualidade, aos seus modos de expressar corporalmente". Nesse mesmo sentido, Beccalli e Gomes (2011, p. 1090) entendem o uso do termo Práticas Corporais em substituição ao termo atividade física, reconhecendo que a "nova designação opera com outro universo simbólico, trazendo novas possibilidades instituintes" que procuram se distanciar da carga semântica atrelada ao modelo biomédico.

Por esse entendimento, os alongamentos, as ginásticas, os jogos, os esportes, quando tratados pelo prisma do conceito de Práticas Corporais, enquanto expressão/percepção

\footnotetext{
${ }^{2} \mathrm{O}$ sentido atribuído ao cuidado neste texto diverge da perspectiva do senso comum, isto é, não vamos limitar o entendimento do cuidado em saúde ao sentido de métodos e recursos terapêuticos. De acordo com Anéas e Ayres (2011) e Ayres (2004a; 2004b) cuidado é pensado como uma categoria filosófica e prática ante ações de saúde que acontece a partir da interação entre sujeitos visando ao alívio de sofrimentos e/ou o bem estar. Assim, o cuidado se situa no diálogo produtivo entre os saberes estruturados e as categorias subjetiva da vida.
} 
corporal subjetiva, de aprendizado pelas experiências do corpo, pela escuta e pela conquista da autonomia, são considerados produtores do cuidado humanizado às pessoas. Coerentes com essa percepção, podemos assumir, então, as Práticas Corporais, assim como fazem Fraga, Carvalho, Gomes (2012), como eixo de uma política de formação em EF transformadora, por entender suas potenciais afinidades com o cuidado e com a atenção integral humanizada e socialmente referenciada.

\section{Outra/Nova Perspectiva: Prática}

Quando tratamos da dimensão prática estamos nos remetendo aos aspectos mais estritamente relacionados à intervenção profissional. Nesse caso, a partir das construções sobre a dimensão política, de ordem conceitual e discursiva, surgem necessidades de tornar coerentes as reflexões sobre as ações da intervenção. Afinal, as práticas unicamente baseadas nos conhecimentos técnico-procedimentais e nos métodos prescritivos certamente não condizem com os fundamentos da Saúde Coletiva, do SUS, do cuidado na integralidade e das Práticas Corporais.

Isso significa, também no cenário da prática profissional, que o corpo em movimento tradicionalmente objeto de intervenção através da ótica biomédica, limitada aos aspectos fisiológicos, anatômicos e epidemiológicos, deve ser analisado pela ótica social, cultural, econômica, afetiva, psicológica, reconhecendo o corpo, em interação constante com o meio, como expressão e contato com o mundo. Ceccim e Bilibio (2007, p.48) acreditam que a EF é propriamente sabedora da existência do corpo em vários sentidos e que o seu trabalho é a "corporalidade, a produção de uma corporeidade virgem e vivaz".

Nesse sentido, as considerações sobre aspectos da micropolítica do trabalho em saúde ${ }^{3}$ tornam-se referência também para a intervenção e formação em EF. As formulações sobre trabalho vivo em ato e sobre as tecnologias do cuidado em saúde certamente contribuem para a reflexão acerca da ressignificação da qualificação desse profissional, principalmente pensando em sua prática nos espaços de atenção básica ${ }^{4}$ na rede do SUS.

Acerca disso, alguns conceitos são importantes a serem considerados, como o de trabalho vivo em ato, que representa o encontro na ação de saúde, o momento exato da produção do cuidado, fruto da relação direta e dinâmica entre profissional da saúde e o usuário, estabelecida pelo contato interpessoal e que não se restringe a receitas e protocolos genéricos. No momento do encontro, tramas subjetivas são estabelecidas e saberes são trocados, ou seja, trata-se de um trabalho criador em ato (MALTA; MERHY, 2003).

Contudo, é possível identificar no trabalho vivo em ato a co-presença de trabalho morto, outro conceito relevante. O trabalho morto seriam os aparelhos, ferramentas e os instrumentos físicos que já foram produzidos anteriormente por alguém e que, por isso, representam o trabalho morto no ato de produção da saúde. Ainda compõe o processo de trabalho elementos que são considerados vivos e mortos simultaneamente, como o saber técnico, tecnológico e metodológico utilizado na produção da saúde. Embora no momento do processo de trabalho esse complexo saber-fazer se legitime como vivo, na condição de

\footnotetext{
${ }^{3}$ Para Feuerwerker (2014), é interessante entender a micropolítica do trabalho em saúde como o desenho e a dinâmica em rede social, portanto, relacional, estabelecida no cenário específico de protagonismo entre o profissional da saúde e o usuário dos serviços, no plano molecular, a partir das subjetivações e relações de poder. ${ }^{4}$ A atenção básica, contato preferencial do usuário com o sistema de saúde, caracteriza-se pelo trabalho em equipe e com delimitação regionalizada, formado por ações de âmbito coletivo e individual no tocante a promoção, proteção, prevenção, diagnóstico, tratamento, reabilitação e manutenção da saúde. "Orienta-se pelos princípios da universalidade, da acessibilidade e da coordenação do cuidado, do vínculo e continuidade, da integralidade, da responsabilização, da humanização, da equidade e da participação social" (BRASIL, 2006).
} 
conhecimento anteriormente construído e reproduzido ele representa um trabalho morto, por ser da dimensão passiva do ato.

Contrariando o modelo convencional, que privilegia as duas dimensões do trabalho morto nos processos de trabalho em saúde, Ceccim e Bilibio (2007, p. 52) acreditam que na EF este trabalho deve estar centrado no trabalho vivo, "[...] dimensão produtiva com potência para escapar da captura do trabalho morto e dos modelos predeterminados de produção da saúde". O trabalho da EF na construção da saúde não representa um produto que é consumido posteriormente ao ato de sua produção pelo seu profissional, como uma mercadoria, que é primeiro produzida e depois comercializada. O trabalho da EF na construção da saúde é, na verdade, especialmente pensando a inserção do professor de EF no cenário da atenção básica, produto do encontro de profissional e usuário, no ato, sendo produzido e consumido simultaneamente. Ou seja, o cuidado é produto vivo em ato que não pode ser capturado ou subjugado pelo trabalho morto. O que também não significa dizer que aparelhos, instrumentos, estruturas físicas e outros produtos-meios devam ser descartados.

Contudo, mais uma vez utilizando os aspectos da micropolítica do trabalho em saúde, percebemos que as tecnologias leves de produção do cuidado podem ganhar centralidade em detrimento das tecnologias duras e leve-duras. Esses termos se referem ao acervo tecnológico do trabalho em saúde, as ferramentas materiais e não materiais de uso laboral. Para Merhy e Franco (2008), as tecnologias duras são os instrumentos físicos de trabalho, as tecnologias leve-duras são o saber técnico estruturado e as tecnologias leves são os elementos frutos das relações entre os agentes da ação cuidadora de saúde, materializadas no ato do encontro.

Para o professor de EF no espaço de intervenção na saúde, as tecnologias duras representam os instrumentos e aparelhos de ginástica, os calçados e vestimentas adequados para as vivências, os materiais desportivos, os equipamentos de análise corporal. Já como tecnologias leves-duras podemos perceber os conhecimentos estruturados sobre cinesiologia, fisiologia do exercício, anatomia, epidemiologia, educação do corpo, antropologia, assim como os métodos e técnicas do treinamento, das ginásticas, das danças, dos esportes, da biomecânica do movimento. Em outro sentido, as tecnologias leves dizem respeito à sensibilidade do profissional em perceber e dar vazão às mais diversas necessidades do usuário em saúde, a partir do corpo, fruto do encontro, da escuta, com significados sociais, históricos, culturais, psicológicos, anatômicos e biológicos.

De acordo com a necessidade e o modo de produzir saúde, o profissional utiliza as três tecnologias dando prevalência a uma ou outra. Sabe-se, por exemplo, que a prática profissional da EF na esfera da saúde esteve sempre se valendo hegemonicamente do uso das tecnologias duras e leve-duras, consideradas mais estruturadas, pois, na maioria das vezes, os aparelhos, as ferramentas, os procedimentos, as técnicas, os protocolos se sobrepõem às práticas subjetivas, por exemplo, de autoconhecimento e autocuidado, proporcionadas pelo encontro.

É importante reforçar nesse sentido, que quando inserida na produção da saúde, a EF, historicamente, buscou uma intervenção baseada na perspectiva da prática curativa, tratando o usuário como portador de uma demanda/carência específica, como fragmento de um corpo com problemas de ordem biológica, sem subjetividade, sem desejos e sem intenções (DAMICO, 2011). Porém, na direção contrária, as habilidades de escuta, de interação, de percepção da expressão do corpo, de reconhecimento da dimensão histórica, afetiva e social podem subordinar a utilização de instrumentos e aparelhos, assim como da aplicação de métodos e procedimentos, dependendo das necessidades e da característica da intervenção.

Pensando então pela ótica da valorização do trabalho vivo e da utilização das tecnologias leves e pela própria consideração acerca da integralidade na atuação bem como na formação em EF na saúde, é importante considerar a potencialidade de outros profissionais comporem a rede de cuidados. Merhy e Franco (2008) afirmam que um profissional da saúde 
sozinho não dá conta de tais necessidades, reconhecendo, portanto, o trabalhador da saúde sempre como coletivo e interdependente de seus pares. Ou seja, diferente do modelo médicocentrado, uma perspectiva que compreende a saúde como transdisciplinar entende os ambientes de produção da saúde como locais de intervenção e convergência de prática multiprofissional.

Atentos ao cuidado coletivo e de responsabilização compartilhada na intervenção e ainda em crítica ao intenso processo de especialização profissional, Malta e Merhy (2003, p. 65) afirmam que quando "[...] cada especialista se encarrega de uma parte da intervenção, em tese ninguém pode ser responsabilizado pelo resultado do tratamento". Isso, segundo eles, ocasiona uma alienação do profissional em relação à prática e, por fim, a sua baixa capacidade de resolutividade sobre os problemas.

Assim, podemos concordar que "A integralidade não poderá ser [...] alcançada com uma clínica fragmentada por diferentes profissionais com os quais o usuário teria contato em sucessivos encontros" (FERLA; BUENO; SOUZA, 2013, p. 208). O cuidado na integralidade só faz sentido se for pensado como fruto da intervenção do coletivo de trabalhadores da saúde em ação multiprofissional, onde todos os integrantes da equipe tornam-se não só participantes como também responsáveis pela prática cuidadora.

\section{Outra/Nova Perspectiva: Pedagógica}

No que tange a dimensão pedagógica, mais dedicada aos princípios de seleção e de organização dos conhecimentos, dos processos didáticos de ensino-aprendizagem na formação em EF, entende-se que focar o processo na transmissão de saberes baseados unicamente na dinâmica de uma cientificidade técnica é insuficiente e mesmo incoerente com os princípios supramencionados. Pela complexidade e profundidade da formação aqui assumida, do ponto de vista pedagógico a qualificação profissional que se limite a mera exposição do aluno aos conteúdos clássicos não dá conta do aprendizado com sentido, muito menos da formação crítica e autônoma, consciente técnica e eticamente (ABRAHÃO; MERHY, 2014).

É importante discernir que não acreditamos que os saberes técnicos, instrumentais e científicos construídos historicamente devem ser negligenciados ou mesmo subjugados. De fato, a qualificação técnica, com forte base científica, não é dispensável. Porém acredita-se que a acumulação de saberes e conhecimento de natureza técnica representa apenas um dos aspectos a serem levados em consideração para transformar as práticas, mas não o seu foco. "A formação[...] também teria de envolver os aspectos pessoais, os valores e as ideias que cada profissional tem sobre o SUS e os projetos de sociedade implicados nas lutas por saúde" (CECCIM; BRAVIN; SANTOS, 2011, p. 166).

$\mathrm{Na} \mathrm{EF}$, a tradição de primazia do discurso médico fez surgir no currículo uma hegemonia dos saberes vinculados a cientificidade moderna, em que o alicerce da formação é composto predominantemente pelos conhecimentos da área médica. $\mathrm{O}$ que configurou um processo formativo centrado no aprendizado da ciência racionalista com pouco sentido e significado do ponto de vista dos contextos, dos sujeitos e da produção de novos conhecimentos. Sobre outra perspectiva, a formação pode ser reconhecida a partir da crítica, da experiência e da crítica sobre a experiência no ensinar e no aprender em saúde, de maneira a elaborar arranjos capazes de produzir práticas pedagógicas que despertem nexos e, portanto, impactos na esfera dos sentidos.

Essa formação poderia ter capacidade de gerar abalos e sensibilidades não só técnicos como também sociais, morais e éticas. Para tanto, é uma possibilidade arranjar a formação sempre priorizando a problematização realizada de forma crítica e eticamente comprometida com a transformação da realidade. Ou seja, contrária à transmissão mecânica de saberes, o 
ensino pode focar na produção de saberes, sentidos e significados sobre a realidade de maneira problematizadora e, portanto, ativa, visando à formação mais autônoma e comprometida socialmente.

Um caminho nesse sentido é nortear as práticas de ensino pelo permanente contato com a comunidade e com os espaços de encontro profissional, sua estrutura, dilemas e contradições. Romper o tradicional isolamento dos ambientes universitários éimprescindível nesse sentido. Para Feuerwerker e Sena (2002, p.40), a universidade e o mundo do trabalho têm que estar afinados com o mundo da vida, pois o isolamento institucional não potencializa a mudança na formação qualificada. Na realidade, "O mundo real, com sua complexidade, tem que estar ativamente presente na construção das novas maneiras de trabalhar e produzir conhecimento". Ainda para essas autoras, a qualificação profissional com permanente interação com a comunidade de forma horizontal valida expectativas pedagógicas "para superar a dicotomia entre teoria e prática, criando as condições para a ação-reflexão-ação" (FEUERWEKER e SENA, 2002, p. 45).

Evidentemente, o acervo de conhecimentos que compõem o processo formativo a ser considerado pode ser ampliado, sobretudo no que diz respeito às ciências humanas e sociais. O próprio conceito de saúde, sua historicidade, seus determinantes ou mesmo a função social do trabalhador da saúde, no caso do professor de EF, temas atualmente um tanto ausentes nos processos formativos, podem passar a compor esse acervo. Áreas como a filosofia, a sociologia, a antropologia, a psicologia, contribuem para a ampliação dos entendimentos sobre saúde, percebida aqui como transdisciplinar. Nessa reflexão, busca-se não simplesmente incluir novos saberes ao currículo, mas também superar os limites estáticos das áreas de conhecimento, exatamente por entender que a saúde é transdisciplinar, isto é, transita em diferentes campos do saber.

Arranjos pedagógicos/curriculares, na visão de Abrahão e Merhy (2014), baseados na transversalidade, são potentes geradores de intenso movimento entre as fronteiras das disciplinas sem a hierarquia de uma elaboração vertical ou horizontal dos saberes. Corroborando, assim, para a construção do acesso do profissional em formação a diversos conhecimentos de forma oblíqua e de maneira a potencializar a mobilização de ações, gestos, afetos, afecções e conhecimentos.

Essa abordagem do currículo de formação em EF não exclui os campos disciplinares tradicionais, como fisiologia do exercício, anatomia humana, bioquímica, mas certamente descentraliza a área de concentração hegemônica. Nesse caso, os campos da cultura e da pedagogia ganham relevância, ao darem vazão a potencialidades do corpo quanto à expressão, sensação, cuidado.

\section{Considerações finais}

O sentido dos apontamentos e perspectivas explicitados nesta pesquisa bibliográfica revela uma significativa afinidade por um posicionamento que redireciona o entendimento clássico acerca da saúde na formação profissional em EF. Esse sentido possui fundamentação na concepção ampliada de saúde e no campo da EF orienta-se pelo conceito de prática corporal como eixo da formação, em substituição ao termo atividade física. Evidentemente, essa opção reverbera na direção da transformação da própria intervenção profissional, legitimando a validação do trabalho vivo em ato, do uso das tecnologias leves de trabalho em saúde e da responsabilização multiprofissional nos serviços.

Além da clara referência à valorização da relação teoria e prática através do permanente contato com a realidade da prática profissional, a repercussão pedagógica dessa reorientação no processo formativo implica ainda assumir a necessidade de atribuir nexos à construção e reconstrução de conhecimento, enquanto resposta a demandas sociais. Ademais, 
a percepção da saúde como transdisciplinar alude o diálogo com diferentes campos de saber, especialmente das ciências humanas e sociais.

É importante finalmente considerar que a mudança na formação profissional não está clara nem definida, o que temos aqui são provocações e apontamentos que podem ser refletidos no sentido de nortear tal processo. Dessa maneira, as construções sistematizadas neste texto, potencializam as discussões no intento de fomentar o movimento, necessário, de transformação na formação e na própria intervenção profissional da EF no campo da saúde.

\title{
PROSPECTS AND POSSIBILITIES FOR RENEWAL OF VOCATIONAL TRAINING IN PHYSICAL EDUCATION IN THE FIELD OF HEALTH
}

\begin{abstract}
The study is oriented to analyze the perspectives that help in the consolidation of a new way of thinking the formation in Physical Education in the health field, in a cutting that explains the dimensions in politics and pedagogy that concern this formation process. It refers to a bibliographic investigation of conceptual nature, which identifies the contributions of a group of authors, with high affinity with the areas of social and human sciences, related as much as in the fields of health and Physical Education, for a curriculum renovation of the formation in that field. The affinities with collective sciences, the concept of corporal practices, the action in the direct work and the technologies represent the synthesis of the conclusions elaborated.

Keywords: Vocational Training; Physical Education; Health

\section{PERSPECTIVAS Y POSIBILIDADES PARA LA RENOVACIÓN DE LA FORMACIÓN PROFESIONAL EN EDUCACIÓN FÍSICA EN EL CAMPO DE LA SALUD}

\begin{abstract}
Resumen
Este estudio objetivó analizar apuntamientos y perspectivas que contribuyen para la consolidación de una nueva manera de pensar sobre la formación en Educación Física para el campo de la salud, en un recorte que explicita las dimensiones política, práctica y pedagógica que conciernen a ese proceso formativo. Se trata de una investigación bibliográfica, de naturaleza conceptual, que identifica las contribuciones de un grupo de autores con fuerte afinidad con el área de las ciencias humanas y sociales, vinculados tanto al campo de la salud cuanto al campo de la Educación Física, para una renovación curricular de la formación de esa área. Las afinidades con la Salud Colectiva, un concepto de prácticas corporales, la acción en el trabajo directo y las tecnologías leves representan el síntesis de los apuntamientos elaborados.
\end{abstract}

Palabras clave: Formación Profesional; Educación Física; Salud.

\section{Referências}

ABRAHÃO, A. L.; MERHY, E. E. Formação em saúde e micropolítica: sobre conceitosferramentas na prática de ensinar. Interface - Comunic., Saúde, Educ., Botucatu, v. 18, n. 49, p. 313-24, 2014. 
ANÉAS, T. V.; AYRES, J. R. C. M. Significados e sentidos das práticas de saúde:a ontologia fundamental e a reconstrução do cuidado em saúde. Interface - Comunic., Saúde, Educ., v.15, n.38, p. 651-62, 2011.

AYRES, J. R. C. M.Cuidado e reconstrução das práticas de Saúde. Interface - Comunic., Saúde, Educ., v.8, n.14, p.73-92, 2004a.

O cuidado, os modos de ser (do) humano e as práticas de saúde. Saúde e Sociedade, v.13, n.3, p.16-29, 2004 b.

AYRES, J.R.C.M. et al. Caminhos da integralidade: adolescentes e jovens na Atenção Primária à Saúde. Interface - Comunic., Saúde, Educ., Botucatu v.16, n.40, p.67-81, 2012.

BECCALLI,M. B.; GOMES, I. M. Das Críticas às Possibilidades: perspectivas de atuação da Educação Física em Saúde Coletiva. Rev. Bras. Ciênc. Esporte, Florianópolis, v. 33, n. 4, p. 1085-1092, 2011.

BRASIL. Constituição (1988). Constituição da República Federativa do Brasil. Brasília, DF: Senado, 1988.

Lei $n^{\circ}$ 8080, de 19 de setembro de 1990. Lei orgânica da saúde. Brasília: DF, 1990.

Portaria n. 648/GM, de 28 de março de 2006. Política Nacional de Atenção Básica. Brasília: Ministério da Saúde, 2006.

CANGUIlHeM, G. O normal e o patológico. Tradução Maria Thereza Redig de Carvalho Barrocas. 6. ed. Rio de Janeiro: Forense Universitária, 2009.

CARVALHO, Y. M. Entre o Biológico e o Social: tensões no debate teórico acerca da Saúde na Educação Física. Motrivivência, Florianópolis, n. 24, p. 97-105, 2005.

CARVALHO, Y. M. Promoção da Saúde, Práticas Corporais e Atenção Básica.In:BRASIL. MINISTÉRIO DA SAÚDE. Revista Brasileira Saúde da Família, Editora MS: Brasília, 2006. p. 33-45.

CECCIM, R. B.; BILIBIO, L. F. S. Singularidades da educação física na saúde: desafios à educação de seus profissionais e ao matriciamento interprofissional. In: FRAGA, B. A., WACHS, F. (Org.). Educação Física e Saúde Coletiva: Políticas de Formação e Perspectivas de Intervenção. Porto Alegre: Editora da UFRGS, 2007. p. 47-62.

CECCIM, R. B.; BRAVIN, F. P.; SANTOS, A. A. Educação na saúde, saúde coletiva e ciências políticas: uma análise da formação e desenvolvimento para o Sistema Único de Saúde como política pública. Lugar comum, Rio de Janeiro, n. 28, p. 159-180, 2011.

CECCIM, R. G.; FEUERWERKE, L. C. M. Mudança na graduação das profissões de saúde sob o eixo da integralidade. Caderno de Saúde Pública, Rio de Janeiro, v. 20, n. 5. p. 14001410, 2004.

DAMICO, J. Rasuras disciplinares e amputação de fazeres. Movimento. Porto Alegre, v. 17, n. 03, p. 269-287, 2011. 
FERLA, A. A.; BUENO, A.; SOUZA, R. Educação física e saúde coletiva: o que pode a ideia de integralidade na produção de mudanças no trabalho e na educação dos profissionais? In: FRAGA, A. B.; CARVALHO, Y. M.; GOMES, I. M. (Org.). As práticas corporais no campo da saúde. São Paulo: Hucitec, 2013. p. 198-226.

FEUERWERKER, L. C. M.; SENA, R. R. Contribuição ao movimento de mudança na formação profissional em saúde: umaavaliação das experiências UNI. Interface - Comunic, Saúde, Educ, Botucatu, v. 6, n. 10, p.37-50, 2002.

FEUERWERKER, L. C. M. Micropolítica e saúde: produção do cuidado, gestão e formação. Porto Alegre: Rede UNIDA, 2014.

FRAGA, A. B.; CARVALHO, Y. M.; GOMES, I. M. Políticas de Formação em Educação Física e Saúde Coletiva. Trab. Educ. Saúde, Rio de Janeiro, v. 10 n. 3, p. 367-386, 2012.

FREITAS, F. F.; BRASIL, F. K.; SILVA, C. L.Práticas corporais e saúde: novos olhares. Rev. Bras. Cienc. Esporte, Campinas, v. 27, n. 3, p. 169-183, 2006.

MALTA, D. C.; MERHY, E. E.A micropolítica do processo de trabalho em saúde: revendo alguns conceitos. Rev. Min. Enf., v. 7, n. 1, p. 61-66, 2003.

MANIFESTO de São Paulo para a promoção da Atividade Física nas Américas. Rev. Bras. Ciênc. E Mov. Brasília, v. 8, n. 1, p. 63-66, 2000.

McARDLE, W. D., KATCH, F. I., KATCH, V. L. Fisiologia do exercício: energia, nutrição e desempenho humano. 6.ed. Rio de Janeiro: Guanabara Koogan, 2008.

MERHY, E. E.; FRANCO, T. B. Trabalho em Saúde. In: PEREIRA, I. B; LIMA, J. C. F. (Org.). Dicionário da Educação Profissional em Saúde. 2. ed. Rio de Janeiro: EPSJV, 2008. p. 427-432.

MINAYO, M. C. S.; HARTZ, Z. M. A.; BUSS, P. M. Qualidade de vida e saúde: um debate necessário. Ciência \& Saúde Coletiva, Rio de Janeiro, v. 5, n. 1, p. 7-18, 2000.

PALMA, A. Educação física, corpo e saúde: uma reflexão sobre outros "modos de olhar". Rev. Bras. Cienc. Esporte, v. 22, n. 2, p. 23-39, 2001.

Recebido em: $24 / 06 / 2015$

Revisado em: 18/10/2015

Aprovado em: 20/10/2015

Endereço para correspondência:

ef.paulonascimento@gmail.com

Paulo Magalhães Monard Nascimento

Universidade Federal do Amapá

Rod. Juscelino Kubitscheck, S/N - Jardim Marco Zero

68903-419 - Macapá, AP - Brasil 